\title{
Supporting materials.
}

\section{MD parameters.}

Table 1: Atomic partial charges added to the Amber94 Parameter Set.

\begin{tabular}{|c|c|c|}
\hline & $\mathrm{Ru}$ & $1.7 \mathrm{e}$ \\
\hline \multirow[t]{3}{*}{ Bipyridine } & $\mathrm{N}_{1}$ & -0.9 \\
\hline & $\mathrm{C}_{2-5}$ & -0.25 \\
\hline & $\mathrm{H}_{3-6}$ & 0.3 \\
\hline \multirow[t]{5}{*}{ Imidazole } & $\mathrm{N}_{E 2}, \mathrm{~N}_{D 1}$ & -0.9 \\
\hline & $\mathrm{C}_{E 1}, \mathrm{C}_{G 1}, \mathrm{C}_{D 2}$ & 0.4 \\
\hline & $\mathrm{H}_{D 1}$ & 0.3 \\
\hline & $\mathrm{C}_{B}$ & -0.6 \\
\hline & $\mathrm{H}_{B 1}, \mathrm{H}_{B 2}, \mathrm{H}_{B 3}$ & 0.3 \\
\hline \multirow[t]{3}{*}{ Donor } & $\mathrm{Cu}$ & 0.7 \\
\hline & $\mathrm{S}_{G}^{*}(\mathrm{Cys} 112)$ & -0.5 \\
\hline & $\mathrm{N}_{D 1}^{*}($ His46,His 117) & -0.64 \\
\hline
\end{tabular}

* Other charges from this residue are unchanged. 